\title{
The Dependence of Natural Graphite Anode Performance on Electrode Density
}

\author{
Joongpyo Shim and Kathryn A. Striebel* \\ Lawrence Berkeley National Laboratory, Environmental Energy Technologies Division \\ Berkeley, CA 94720, USA
}

\begin{abstract}
The effect of electrode density for lithium intercalation and irreversible capacity loss on the natural graphite anode in lithium ion batteries was studied by electrochemical methods. Both the first-cycle reversible and irreversible capacities of the natural graphite anode decreased with an increase in the anode density though compression. The reduction in reversible capacity was attributed to a reduction in the chemical diffusion coefficient for lithium though partially agglomerated particles with a larger stress. For the natural graphite in this study the potentials for Li (de)insertion shifted between the first and second formation cycles and the extent of this shift was dependent on electrode density. The relation between this peak shift and the irreversible capacity loss are probably both due to the decrease in graphite surface area with compression.
\end{abstract}

Key words; lithium ion battery, intercalation, irreversible capacity loss, natural graphite, electrode density 


\section{Introduction}

The lithium rechargeable battery is expected to be a strong candidate for the energy source in electric and hybrid vehicles (EV and HEV) because of it's high energy and power densities. Various forms of synthetic graphite have proven to be excellent lithium intercalation compounds and are widely used as the anode active material in consumer lithium rechargeable batteries. However, the cost of the synthetics is prohibitive for EV applications. Therefore, recent effort has been directed at the purification and performance of various natural graphites (NG), with a target price below $\$ 10 / \mathrm{kg}$. Many NG's have been studied electrochemically to characterize their reversible capacity and first cycle irreversible capacity loss (ICL), or first cycle coulombic inefficiency. The dependence of performance on the particle size [1], surface area [2], surface modification [3,4], and mechanical milling $[5,6]$, in various organic electrolytes has been studied, as well as the dependence on the composition of the electrolyte $[7,8]$. The ICL is due to primarily to the formation of a passivating solid electrolyte interface (SEI) layer by the decomposition of the electrolyte to form both as SEI layer and gaseous products on the surface of graphite during the initial charge/discharge cycles [9]. The ICL has been shown to increase linearly with an increase in the surface area of graphite $[1,10,11]$. If the surface area or porosity of a graphite electrode is reduced by changes in the polymer binder content or pressing, the practical capacity and the ICL should be affected. In battery manufacturing, the pressing of the electrode is a critical step in the production of high-energy cells. However, there is limited information regarding changes in the ICL for a given natural graphite anode by pressing, where both the surface area of exposed graphite can change as well as the inventory of electrolyte though a reduction in anode porosity. Reports on the relationship between the capacity of graphite and density of pressed anodes suggest that a reduction in the electrode porosity by pressing leads to decreased capacity due to longer diffusion paths and/or a disruption of the graphite morphology $[12,13,14,15]$. With high enough pressure on the anode, damage to graphite particle has been reported [13].

In this work, we studied the performance of a flaky natural graphite from Superior Graphite in anodes prepared with differing levels of compression. Though careful 
examination of the formation of these anodes in half-cells, we've studied some of the changes occurring during this very popular step in anode production.

\section{Experimental}

The anode consisted of natural graphite (90\%, SL20, Superior Graphite Co.), PVdF binder (10\%, Kureha 9130) and $\mathrm{Cu}$ foil current collector (thickness $25 \mu \mathrm{m})$. The mixture of natural graphite was dispersed in PVdF/1-methyl-2-pyrrolidinone (NMP) solution to make a slurry. They were cast with a knife coater onto $\mathrm{Cu}$ foil and dried under vacuum at $120^{\circ} \mathrm{C}$ for $12 \mathrm{~h}$. The active loading of the anode was $5.0 \pm 0.1 \mathrm{mg} / \mathrm{cm}^{2}$ and thickness was $70 \mu \mathrm{m}$ before pressing. Dried anodes were compressed with a bench-top press and the apparent electrode density was measured from the thickness of electrode before and after pressing. Swagelok half-cells were assembled with $1 \mathrm{~cm}^{2}$ anode, porous separator (Celgard 2500), Li foil reference/counter electrodes and electrolyte $\left(1 \mathrm{M} \mathrm{LiPF}_{6}+\mathrm{EC} / \mathrm{DEC}, \mathrm{LP} 40\right.$ from Merck). All cells were assembled for testing in an Ar-filled glovebox. Electrochemical characterizations of the natural graphite anode were carried out by charge/discharge cycling, cyclic voltammetry (CV) and electrochemical impedance spectroscopy (EIS). The graphite anodes were cycled with an Arbin battery cycler between $0.01 \mathrm{~V}$ and $1.0 \mathrm{~V}$ (vs. $\mathrm{Li} / \mathrm{Li}^{+}$), using a taper charge at $0.01 \mathrm{~V}$ until the current dropped below $\mathrm{C} / 20$. Cyclic voltammetry was carried out by VMP Potentiostat/Galvanostat from BioLogic. Electrochemical impedance spectroscopy was measured by Solartron 1260 frequency response analyzer with Solartron 1286 electrochemical interface in the frequency range between $0.005 \mathrm{~Hz}$ and $100 \mathrm{kHz}$.

\section{Results and Discussion}

\section{Formation}

The natural graphite electrodes were formed with two low-rate $(\mathrm{C} / 25)$ cycles between $\mathrm{OCV}, 0.01$ and $1.0 \mathrm{~V}$ vs. $\mathrm{Li} / \mathrm{Li}^{+}$. This is equivalent to about $14 \mathrm{~mA} / \mathrm{g}$ or $72 \mu \mathrm{A} / \mathrm{cm}^{2}$. This method is used to build-up a smooth stable solid electrolyte interface (SEI) layer by the 
slow decomposition of the electrolyte solvents on the surface of graphite $[9,16,17]$. Fig. 1 shows the voltage profiles of unpressed and pressed graphite electrodes for the first and second cycles. The discharge capacities for both unpressed and pressed electrodes were more than $350 \mathrm{mAh} / \mathrm{g}$, close to the theoretical capacity $(372 \mathrm{mAh} / \mathrm{g})$ of graphite. The shape of the voltage profiles for the first charge of the SL20 natural graphite anode are quite different from the second charge, while the two discharge curves are quite similar in shape. This reflects the irreversible processes always present with carbon anodes on the first charge and will be discussed below. Fig. 2 shows the dependence of the reversible and irreversible capacities for the natural graphite electrodes on electrode density. Irreversible capacity loss (ICL, Q ${ }_{\text {irrev }}$ ) for all of the electrodes fell between 60 and $100 \mathrm{mAh} / \mathrm{g}$, or 7$12 \%$. Both the reversible and irreversible capacities decreased slightly with increasing electrode density. Electrode pressing will decrease the porosity of the anode and may also decrease the active surface area of the SL-20 natural graphite electrode. In addition, the flaky graphite may tend to agglomerate through surface attraction between the layers, leading to effectively larger particles. Previously, the ICL during formation has been directly related to the surface area of graphite, regardless of particle size, while the reversible capacity is only affected by the particle size of graphite [1,2]. Both of the trends in Fig. 2 can be explained if the natural graphite particles are agglomerating into larger particles having a lower surface area with increased compression. In fact, recent SEM pictures of the surface of pressed SL-20 anodes tend to confirm this agglomeration [18].

Fig. 3 shows the dQ/dV plots, calculated from the data in Fig. 1, for the first and second formation cycles of natural graphite electrodes with three different pressed densities. There are three clear peaks for lithium intercalation/deintercalation between $0.25 \mathrm{~V}$ and $0.05 \mathrm{~V}\left(\mathrm{vs} . \mathrm{Li}^{2} / \mathrm{Li}^{+}\right.$). Ohzuku et al. reported the intercalation mechanism and the identification for each stage of graphite by measuring XRD and open circuit voltage (OCV) of a lithium/graphite cell [19]. They assumed the existence of 1, 2, 3, 4 and 8thstages and the transition of each stage according to the following scheme.
Region (I)
$\mathrm{LiC}_{6}(1$ st-stage $)$
$\mathrm{LiC}_{12}$ (2nd-stage)
Region (II)
$\mathrm{LiC}_{12}$ (2nd-stage)
$\mathrm{LiC}_{18}$ (2nd-stage) 
$\begin{array}{llllll}\text { Region (III) } & \mathrm{LiC}_{18} \text { (2nd-stage) } & \leftrightarrows & \mathrm{LiC}_{27} \text { (3rd-stage) } & \leftrightarrows & \mathrm{LiC}_{36} \text { (4th-stage) } \\ \text { Region (IV) } & \mathrm{LiC}_{36} \text { (4th-stage) } & \leftrightarrows & \mathrm{LiC}_{72} \text { (8th-stage) } & & \end{array}$

The three peaks for charge and discharge in Fig. 3 are assigned to Regions (I), (II) and (IV). It is clear from Fig. 3 that peak potentials and peak heights vary from the first to the second charging processes. In addition, the potential for each of the lithium intercalation and deintercalation peaks is shown as a function of electrode density in Fig.s 4a and 4b, respectively. These data show that the peak potentials for the charging stages (lithium intercalation) are decreasing slightly, while those for the discharging stages (lithium deintercalation) are increasing slightly, with increases in the electrode density. In other words, the intercalation is becoming less reversible with increased electrode density. The decrease in anode reversibility with compression can be seen even more clearly in Fig. 5, which shows the peak potential difference $(\Delta \mathrm{E})$ of each region between charge and discharge. This hysteresis (difference) between charge and discharge is always observed, even for very slow rate cycling and slow cyclic voltammetry [20,21]. This behavior for lithium intercalation/deintercalation is an intrinsic property of graphite. Changes in this intrinsic $\Delta \mathrm{E}$ with an electrode density, or other parameters are not commonly reported. The size of the $\Delta$ Es for the region (I) and (II) Li intercalation processes are higher than those in region (IV), for both first and second cycle. However, the density effect (slope) appears quite similar for the different stages. The influence of anode density on this process even at slow rates, is possibly due an increased stress on the graphite particles. However, an increased stress on the particles might also be expected to lead to a slowing of the lithium diffusion through the graphite planes. This effect was examined below with variable rate measurements. .

Another thing to note in Figs. 4 and 5 is the consistent potential difference between the first cycle and second cycle charging (Li intercalation) peaks in 4A as compared with no differences between first and second discharge peak potentials (Li deintercalation peaks) in 4B. This a reflection of the peak potential shift between the first and second charge in Fig. 3. Differences are expected between the first and second charges due to SEI 
formation, however, they are not expected in the $\mathrm{Li}$ intercalation region. In addition, this potential shift appears to be independent of anode compression. The change in intercalation energy between the first and second cycles would appear to be an obvious result of the different chemistry of the graphite before and after the irreversible first-cycle processes. However, it is usually expected that the irreversible SEI layer will have formed prior to the start of the true intercalation process. This shift in energies between the first and second cycles is a clear indication that the irreversible first cycle process in this natural graphite is NOT finished until the anode is fully charged with lithium.

To understand the role of SEI formation in this process, it is interesting to examine the charges associated with the different processes. The high-potential portion of $\mathrm{dQ} / \mathrm{dV}$ plot for an anode compressed to $65 \mu \mathrm{m}$ is shown in Fig. 6. The reduction of the electrolyte components are shown clearly on this anode in the peaks at $0.76,1.24$ and $1.66 \mathrm{~V}$, usually attributed to EC, DEC and trace water, respectively. The charge associated with this process was integrated between the $3 \mathrm{~V} \mathrm{OCV}$ and $0.25 \mathrm{~V}$ vs. $\mathrm{Li} / \mathrm{Li}^{+}$, using the curve for the second cycle as the baseline. The charge associated directly with the reaction on the surface of the anode amounted to about $60 \%$ of the total first cycle irreversible capacity. This fraction was found to be independent of anode pressing level for these thin electrodes. The lithium corresponding to the remaining $40 \%$ of the ICL is "lost" in the lithium intercalation region, probably due to the small amorphous fractions within the graphite particles. The result of this added "internal" ICL is to lower the overpotential for Li ion reduction and intercalation compared with the steady state values. This could also be a reflection of chemical changes in or extension of the SEI layer caused by the newly intercalating $\mathrm{Li}$ ions at the lower potentials. Further examination of the graphite morphology, before and after the first intercalation process would be nec. to characterize this process further and is beyond the scope of this work. This conversion appears to be complete once the lowest potential is achieved and thereafter, the kinetic overpotential for the surface for Li ion reduction is uniform for many cycles (not shown). 


\section{Cyclic voltammetry}

Slow-sweep rate $\mathrm{CV}$ is being used extensively to study the rate limiting processes in intercalation electrodes in recent years. Fig. 7 shows the cyclic voltammograms recorded with an unpressed natural graphite electrode measured at scan rates from 0.005 to $0.05 \mathrm{mV} / \mathrm{s}$ after the formation cycles. There are clearly three quasi-reversible peaks that correspond to the stages mentioned above and the $\mathrm{dQ} / \mathrm{dV}$ plot in Fig. 3. In slow scan rate cyclic voltammetry (SSCV), two ranges of scan rate (v) can be observed for lithium intercalation from thin electrode [21]. At low scan rates, the peak current is proportional to $v$, which is typical pseudocapacitance behavior for the accumulation of intercalated species in the bulk of the electrode. This peak current $\left(i_{\mathrm{p}}\right)$ may be expressed by following equation [22]:

$$
i_{\mathrm{p}}=9.39 \times 10^{5} v l A C_{L i}
$$

where $l$ is the thickness of the electrode, $A$ is the apparent surface area of the electrode and $C_{L i}$ is the Li concentration in the carbon.

At higher sweep rates, the peak current is proportional to $v^{1 / 2}$, characteristic of a semiinfinite solid-state diffusion process and the peak current can be expressed by the following equation [23]

$$
i_{\mathrm{p}}=2.69 \times 10^{5} n^{3 / 2} A D_{L i}{ }^{1 / 2} \Delta C_{L i} v^{1 / 2}
$$

where $n$ is the number of electrons per species reaction $\left(1\right.$ for $\left.\mathrm{Li}^{+}\right), D_{L i}$ is the diffusion coefficient of $\mathrm{Li}^{+}$in the solid state and $\Delta C_{L i}$ is the change in Li intercalation in the carbon.

Fig. 8 shows the relationship between the peak current and the scan rate for the lithium intercalation into the unpressed natural graphite anode. These results are consistent with Levi and Aurbach's [21] although they used a much thinner electrode with a different type of graphite (Lonza KS6). Fig. 9 shows the average chemical diffusion coefficient of $\mathrm{Li}^{+}$ion calculated from Eq. [2] and the slopes from Fig. 8 (a). The calculated chemical diffusion coefficient for $\mathrm{Li}^{+}$ion decreased slightly with the increase of electrode density. The porosity of the electrodes, estimated from the thickness of the coating, the density of graphite $(2.26 \mathrm{~g} / \mathrm{cc})$ and the density of PVdF $(1.78 \mathrm{~g} / \mathrm{cc})$, decreased from about $65 \%$ to $40 \%$

with pressing. The decrease in porosity will have an effect on the rate of transport in the liquid phase. However, the diffusivity of Li ion in the electrolyte should be on the order of 
$10^{-6} \mathrm{~cm}^{2} / \mathrm{s}$, and probably not rate-controlling. Since we are assuming the case of semiinfinite diffusion, any increases in apparent particle size should not affect measured diffusivities. However, when the graphite anode is pressed, the stress between graphite planes could be increased. Even a small decrease in the interplanar distance could lead to a large affect on the diffusivity of Li though those planes. .

\section{Electrochemical Impedance Spectroscopy}

Electrochemical impedance spectroscopy was recorded for the same anodes over the frequency range of $60 \mathrm{mHz}$ to $80 \mathrm{kHz}$. The Nyquist plot for pressed natural graphite electrode (density $1.33 \mathrm{~g} / \mathrm{cm}^{3}$ ) is shown in Fig. 10 as a function of the state of charge (SOC). This technique was first proposed by Ho et al. [24] to investigate lithium diffusion in tungsten trioxide thin films. From this method, the Warburg prefactor $\sigma$ is represented following equation [25];

$$
\begin{aligned}
& -Z_{\mathrm{Im}}=\sigma \omega^{-1 / 2} \text { or } Z_{\mathrm{Re}}=\sigma \omega^{-1 / 2} \\
& \sigma=\left[V_{m} / n F A\left(2 D_{L i}\right)^{1 / 2}\right]\left(d V_{o c} / d x\right)
\end{aligned}
$$

where $\mathrm{V}_{\mathrm{m}}$ is the molar volume of lithiated carbon, $d V_{o c} d x$ is the gradient of the opencircuit voltage vs. the composition $x$ in $\mathrm{Li}_{x} \mathrm{C}_{6}, n$ is the number of electrons transferred, and $A$ is the active area. It is difficult to get exact value of $d V_{o d} / d x$ and $\mathrm{V}_{\mathrm{m}}$ from coulombic titration curve because of the staging phenomenon of graphite [26] Therefore, Eq. [4] can be modified to following equation;

$$
\sigma=R T /\left(n^{2} F^{2} A 2^{1 / 2}\right)\left(1 / D_{L i}{ }^{1 / 2} C_{L i}\right)
$$

where $\mathrm{R}$ is the gas constant and $\sigma$ was calculated from the slope of $Z_{\mathrm{Re}}$ or $Z_{\mathrm{Im}} \mathrm{vs} \omega^{-1 / 2}$ in the frequency range of the slope with $45^{\circ}$ observed in Nyquist plot.

Fig. 11 shows the chemical diffusion coefficient $\left(D_{\mathrm{Li}}\right)$ of $\mathrm{Li}$ ion in natural graphite electrode as function of electrode density and SOC, calculated from equation 5 . The value of $D_{\mathrm{Li}}$ ranges from $1.0 \times 10^{-10}$ to $2.5 \times 10^{-13} \mathrm{~cm}^{2} / \mathrm{s}$ in $\mathrm{Li}_{\mathrm{x}} \mathrm{C}_{6}(0.1<\mathrm{x}<0.6)$, which is significantly lower than that calculated from SSCV in Fig. 9. Doyle et. al. [27] have pointed out the difficulties with using the Warburg technique for measuring Li diffusivities in intercalation materials. Under estimations of as much as three orders of magnitude can be expected 
since solid phase diffusion is not the only factor controlling the impedance in the intermediate frequency range. Due to the sloping open circuit potential curves, the finite capacity impedance response of the intercalation electrode dominates the impedance, except for extremely low values of the D. However, the trend of the chemical diffusion coefficients in Fig. 11 to decrease with an increase of electrode density is consistent behavior with Fig. 9.

\section{Conclusions}

The response of a natural graphite anode, compressed to different densities, to lithium (de)intercalation in $1 \mathrm{M} \mathrm{LiPF}_{6}-\mathrm{EC}-\mathrm{DEC}$ was studied with constant current cycling, cyclic voltammetry (CV) and electrochemical impedance spectroscopy (EIS). Compressing the natural graphite anode led to a slight reduction in both the reversible capacity and the irreversible capacity loss for first cycle. The peak potentials for lithium intercalation/deintercalation were shifted by compressing electrode. The chemical diffusion coefficient of $\mathrm{Li}$ ion through the graphite particles ranged from $8.0 \times 10^{-10}$ to $7.0 \times 10^{-11} \mathrm{~cm}^{2} / \mathrm{s}$ by $\mathrm{CV}$. The chemical diffusion coefficient tended to decrease with increases in Li content and anode density.

\section{Acknowledgement}

We gratefully acknowledge the supply of natural graphite from Superior Graphite Company. This research was funded by the Assistant Secretary for Energy Efficiency and Renewable Energy, Office of Advanced Automotive Technologies, U. S. Department of Energy, under contract number DE- AC03-76SF00098. Some of this work was previously presented as Abstract \#15 at the International Meeting on Lithium Batteries, Monterey, CA, June 2002. 
1. K. Zaghib, G. Nadeau, K. Kinoshita, J. Electrochem. Soc., 147 (2000) 2110.

2. K. Zaghib, F. Brochu, A. Guerfi, K. Kinoshita, J. Power Sources, 103 (2001) 140.

3. T. Tsumura, A. Katanosaka, I. Souma, T. Ono, Y. Aihara, J. Kuratomi, M. Inagaki, Solid State Ionics, 135 (2000) 209.

4. H. Wang, M. Yoshio, J. Power Sources, 93 (2001) 123

5. T. S. Ong, H. Yang, Carbon, 38 (2000) 2077.

6. H. Wang, T. Ikeda, K. Fukuda, M. Yoshio, J. Power Sources, 83 (1999) 141

7. M. Fujimoto, Y. Shoji, Y. Kida, R. Ohshita, T. Nohma, K. Nishio, J. Power Sources, 72 (1998) 226.

8. A. Naji, P. Willmann, D. Billaud, Carbon, 36 (1998) 1347.

9. D. Aurbach, B. Markovsky, I. Weissman, E. Levi, Y. Ein-Eli, Electrochim. Acta, 45 (1999) 67.

10. G.-C. Chung, S.-H. Jun, K.-Y. Lee, M.-H. Kim, J. Electrochem. Soc., 146 (1999) 1664.

11. F. Joho, B. Rykart, A. Blome, P. Novak, H. Wilhelm, M.E. Spahr, J. Power Sources, 97-98 (2001) 78.

12. V. Manev, I. Naidenov, B. Puresheva, P. Zlatilova, G. Pistoia, J. Power Sources, 55 (1995) 211.

13. P. Novak, W. Scheifele, M. Winter, O. Haas, J. Power Sources, 68 (1997) 267.

14. J.S. Gnanaraj, Y.S. Cohen, M.D. Levi, D. Aurbach, J. Electroanal. Chem., 516 (2001) 89.

15. S.-I. Lee, Y.-S. Kim, H.-S. Chun, Electrochim. Acta, 47 (2002) 1055.

16. K. Tatsumi, N. Iwashita, H. Sakaebe, H. Shioyama, H. Higuchi, A. Mabuchi and H.

Fujimoto, J. Electrochem. Soc., 142 (1995) 716.

17. E. Peled, C. Menachem, D. Bar-Tow and A. Melman, J. Electrochem. Soc., 143 (1996) L4.

18. C. W. Wang, Y.-B. Li, A.M. Sastry, J. Shim and K. A. Striebel, J. Electrochem. Soc., submitted, 2003.

19. T. Ohzuku, Y. Iwakoshi, K. Sawai, J. Electrochem. Soc., 140 (1993) 2490.17 
20. J.R. Dahn, Phys. Rev. B, 44 (1991) 9170.

21. M. D. Levi, D. Aurbach, J. Electroanal. Chem., 421 (1997) 79.

22 A.J. Bard and L.R. Faulkner, Electrochemical Methods, Fundamentals and Applications, Wiley, New York, 1980, p.410.

23. A.J. Bard and L.R. Faulkner, Electrochemical Methods, Fundamentals and Applications, Wiley, New York, 1980, p.222.

24. C. Ho, I.D. Raistrick, R.A. Huggins, J. Electrochem. Soc., 127 (1980) 343.

25. P. Yu, B.N. Popov, J.A. Ritter, R.E. White, J. Electrochem. Soc., 146 (1999) 8.

26. N. Takami, A. Satoh, M. Hara, T. Ohsaki, J. Electrochem. Soc., 142 (1995) 371.

27. M. Doyle, J.P Meyers and J. Newman, J. Electrochem. Soc., 147 (2000) 99. 


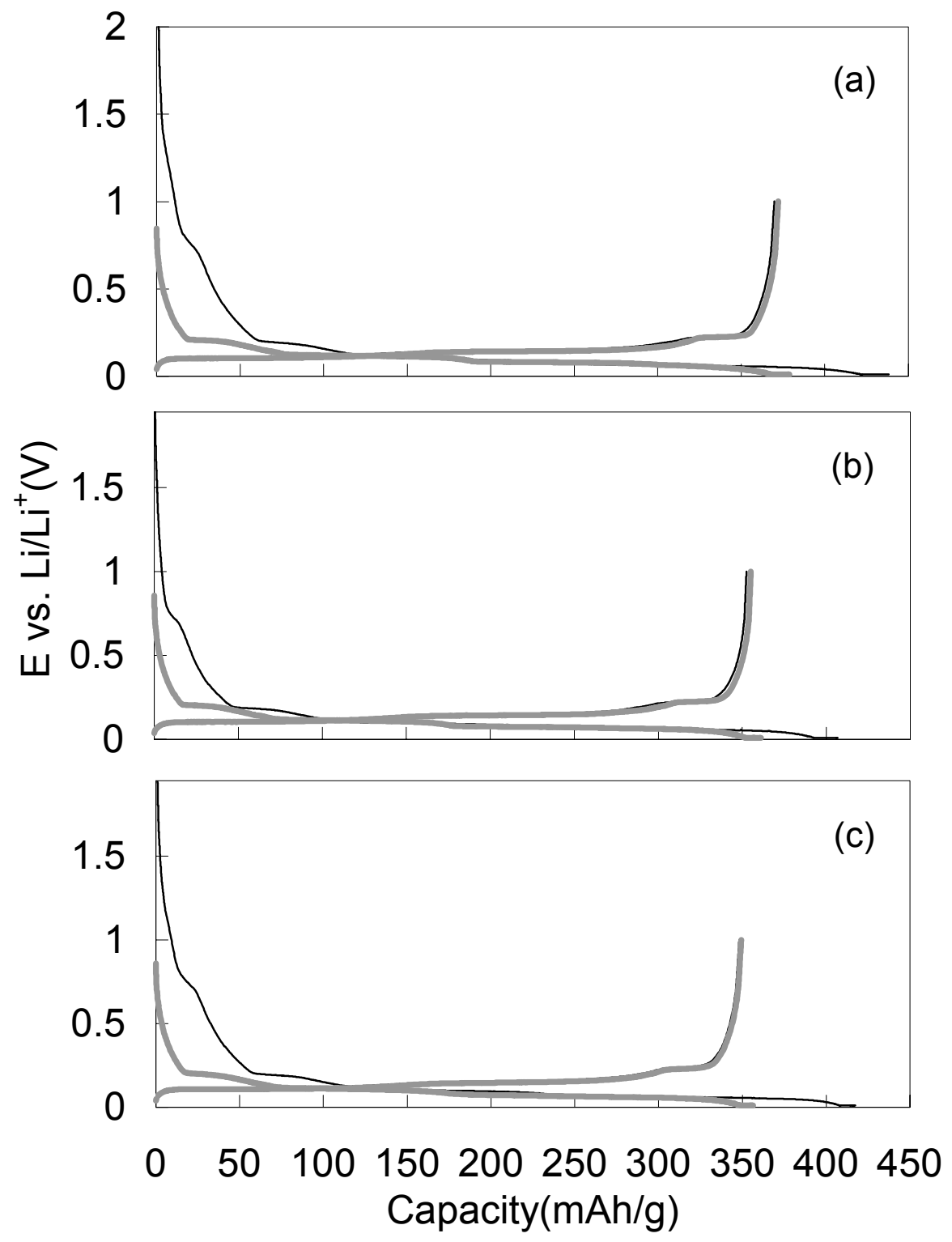

Fig. 1. Voltage profiles of natural graphite electrode for first and second cycles: (a) unpressed electrode $\left(0.76 \mathrm{~g} / \mathrm{cm}^{3}\right)$, (b) pressed electrode $\left(0.9 \mathrm{~g} / \mathrm{cm}^{3}\right)$, (c) highly pressed electrode $\left(1.33 \mathrm{~g} / \mathrm{cm}^{3}\right) ;(-)$ first cycle, $(-)$ second cycle 

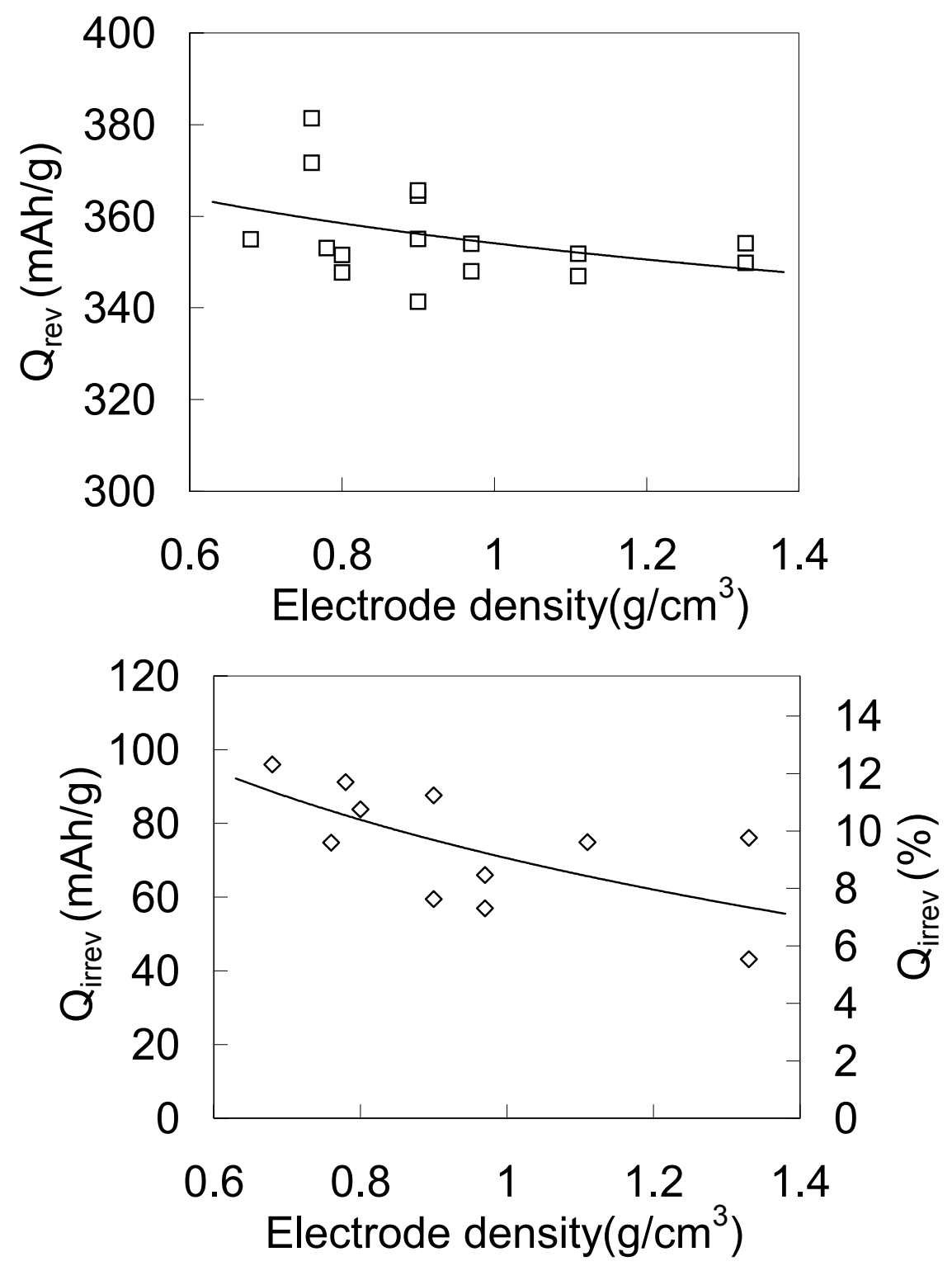

Fig. 2. Reversible (upper figure) and irreversible (lower figure) capacities of natural graphite electrodes for first (a) and second (b) cycles 

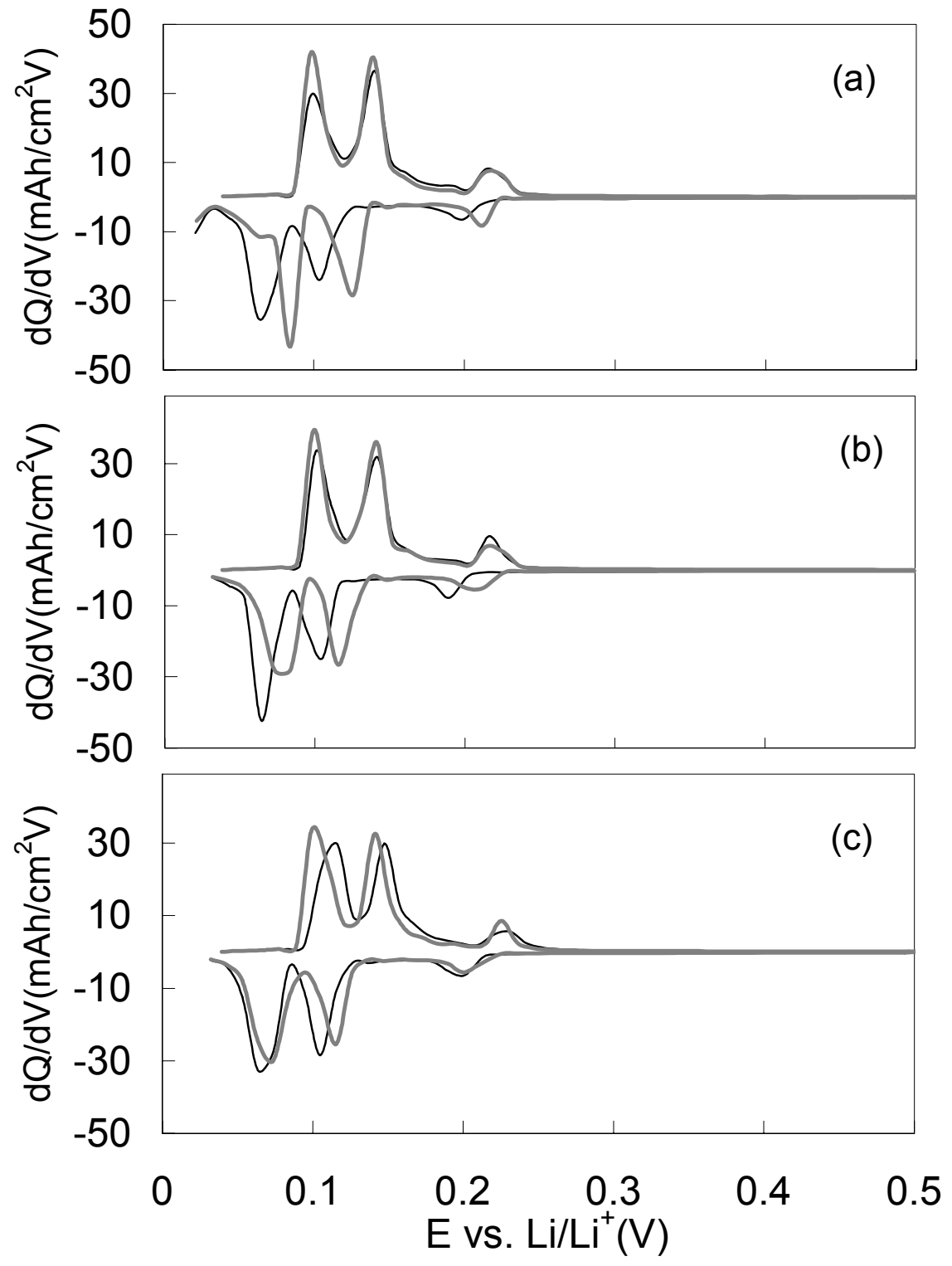

Fig. 3. dQ/dV plots for natural graphite electrode: (a) unpressed electrode $\left(0.76 \mathrm{~g} / \mathrm{cm}^{3}\right)$, (b) pressed electrode $\left(0.9 \mathrm{~g} / \mathrm{cm}^{3}\right)$, (c) pressed electrode $\left(1.33 \mathrm{~g} / \mathrm{cm}^{3}\right)$; $(-)$ first cycle, $(-)$ second cycle 

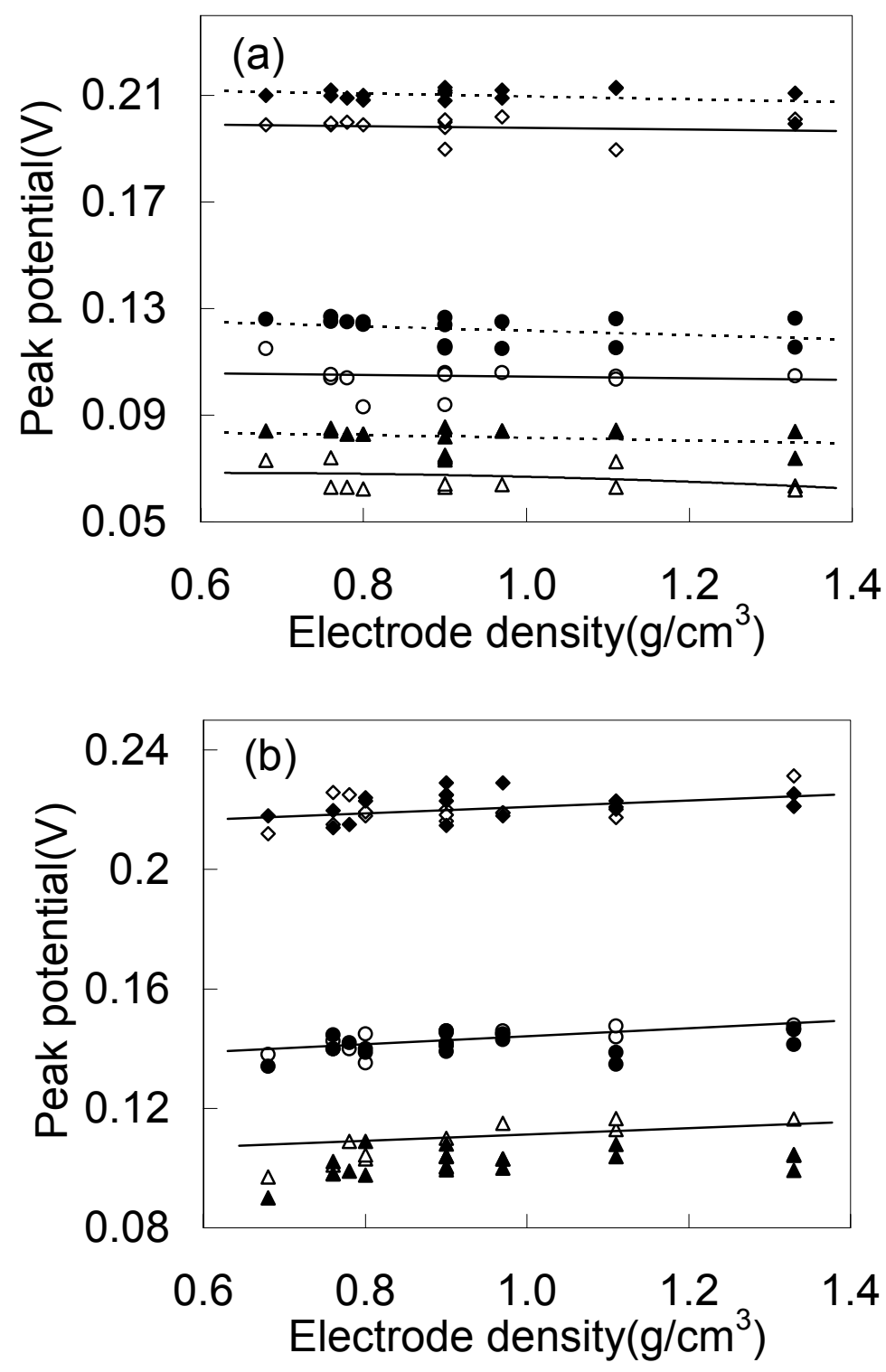

Fig. 4. Peak potential for lithium intercalation/deintercalation into/from natural graphite electrode on electrode density for first (open symbols) and second (filled symbols) cycles: $(\diamond, \diamond)$ Region IV, $(\bigcirc, \bullet)$ Region II, $(\triangle, \mathbf{\Delta})$ Region I: (a) charge, (b) discharge. 


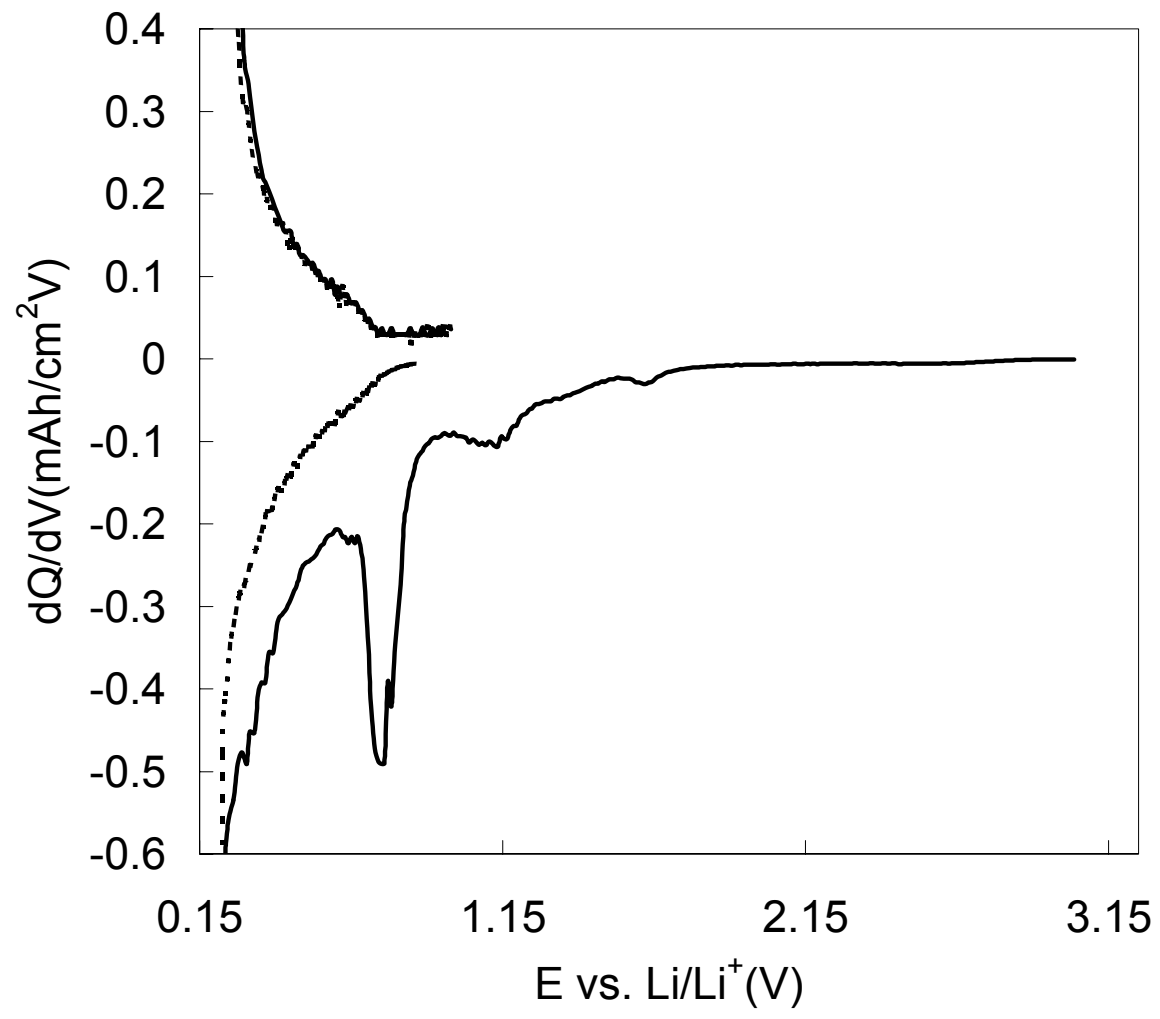

Fig. 5 High potential region of the $\mathrm{dQ} / \mathrm{dV}$ curve calculated from the two $\mathrm{C} / 25$ formation cycles for the pressed electrode $\left(1.33 \mathrm{~g} / \mathrm{cm}^{3}\right)$. solid line: first cycle, dotted line: second cycle 

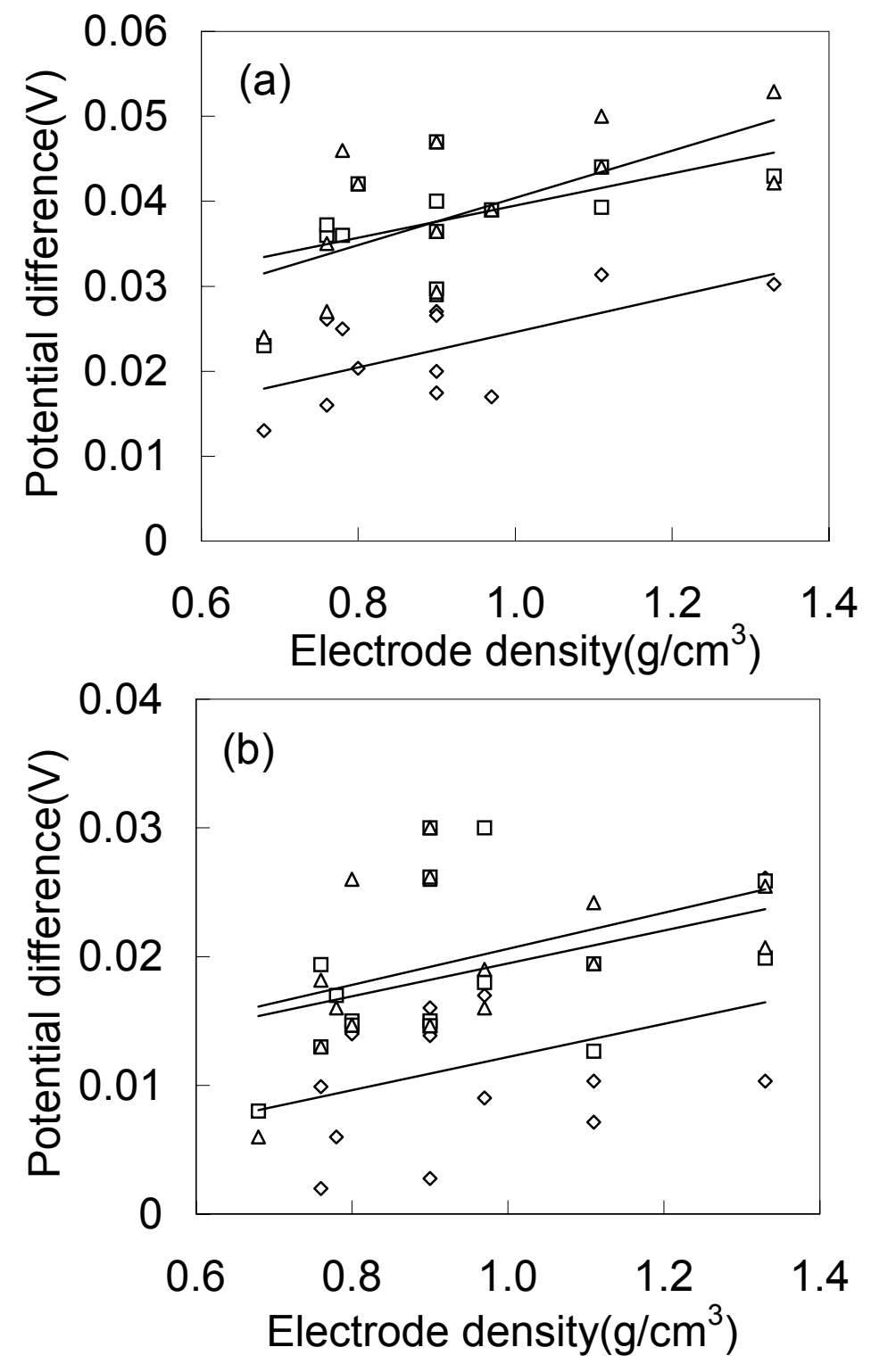

Fig. 6. Peak potential difference for lithium intercalation/deintercalation between charge and discharge: $(\diamond)$ Region IV, $(\square)$ Region II, $(\triangle)$ Region I: (a) first cycle, (b) second cycle. 


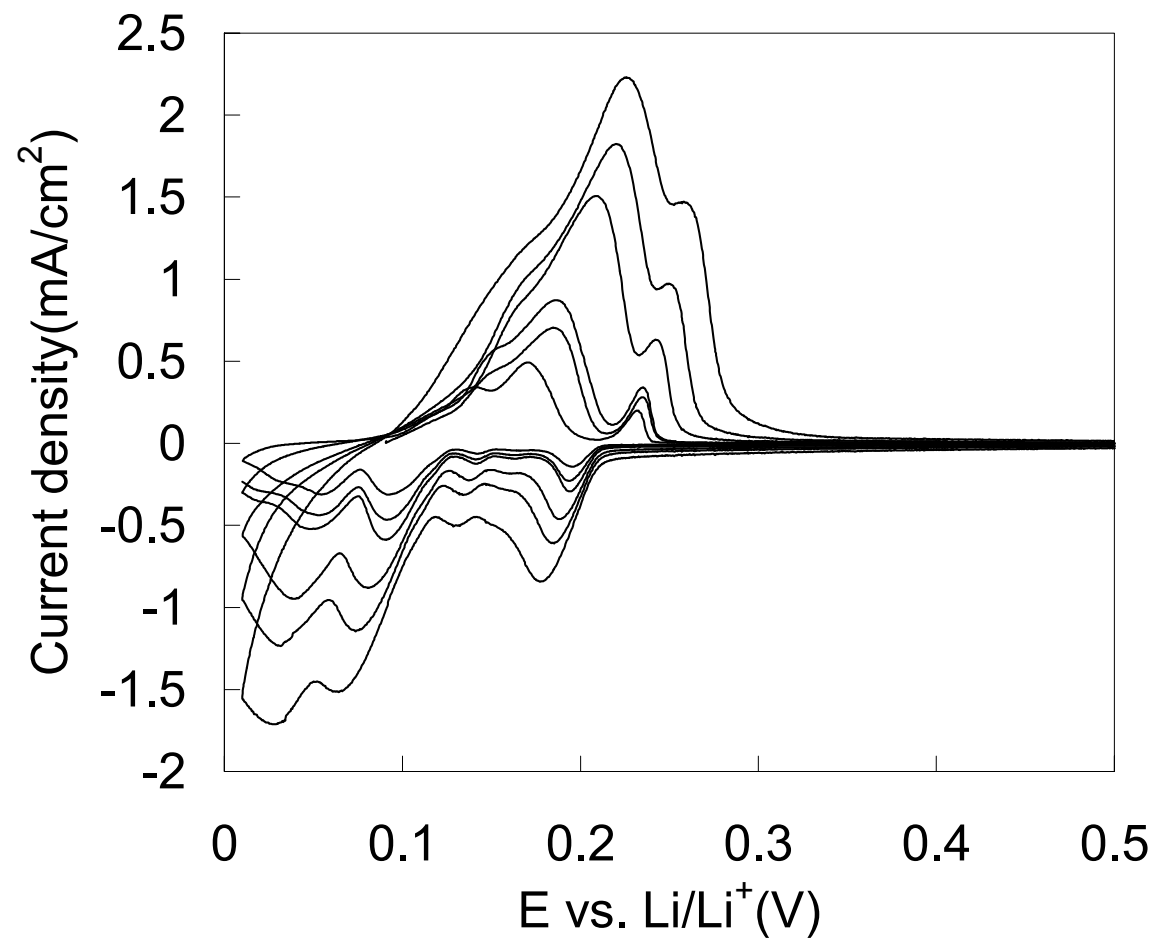

Fig. 7. Cyclic voltammograms for unpressed graphite electrode: Scan rate 0.005$0.05 \mathrm{mV} / \mathrm{sec}$. 

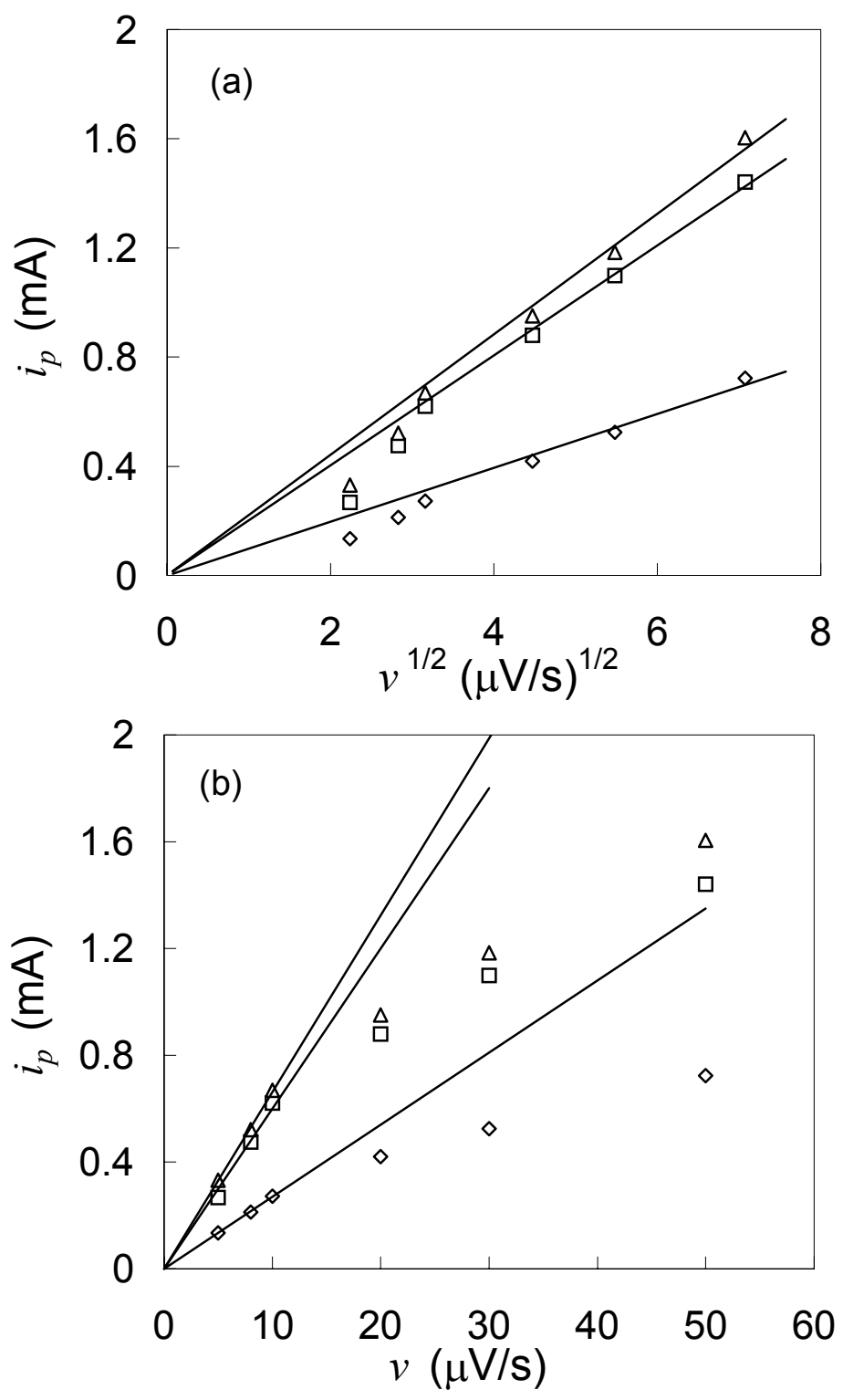

Fig. 8. Peak current on the scan rate for lithium intercalation; Scan rate $0.005-0.05 \mathrm{mV} / \mathrm{s}$; $(\diamond)$ Region IV, $(\square)$ Region II, $(\triangle)$ Region I 


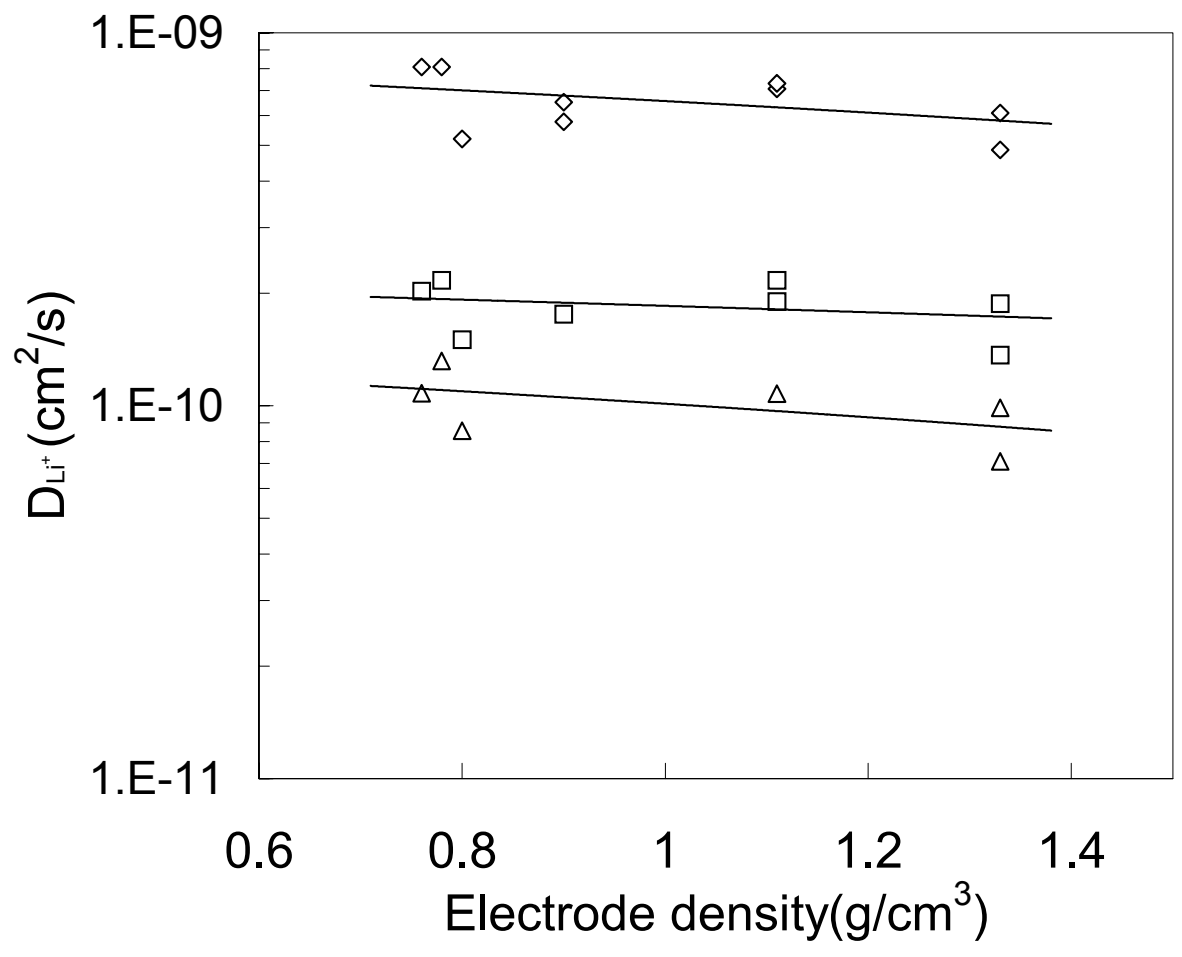

Fig. 9. Average chemical diffusion coefficient of $\mathrm{Li}$ ion calculated from slow scan rate cyclic voltammetry; $(\diamond)$ Region IV, $(\square)$ Region II, $(\triangle)$ Region I 


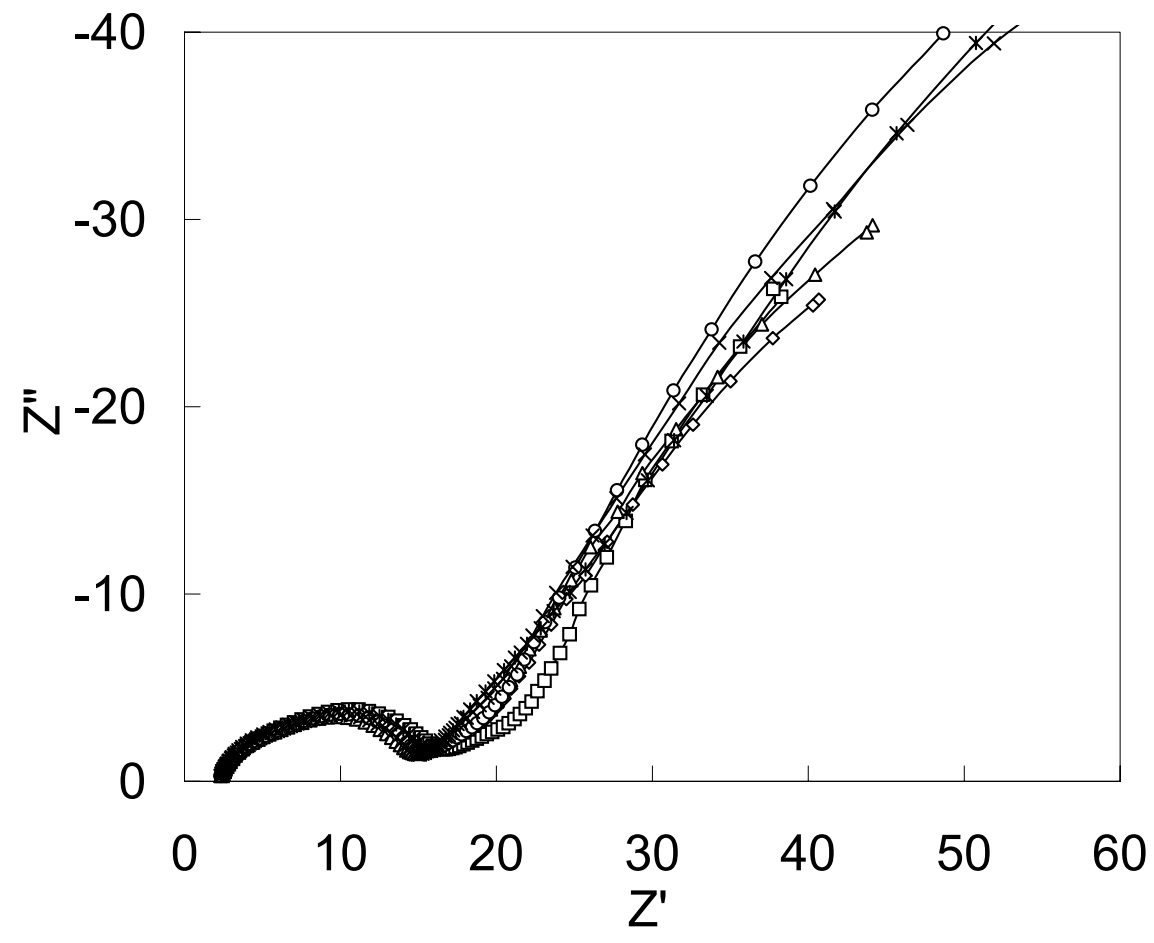

Fig. 10. Nyquist plot of pressed natural graphite anode on SOC; (- $\square-)$ 10\% SOC, (- $\left.\diamond_{-}\right)$ $20 \%$ SOC, (- $\triangle-) 30 \%$ SOC, (-O-) $40 \%$ SOC, (-X-) $60 \%$ SOC, (-*-) $80 \%$ SOC 


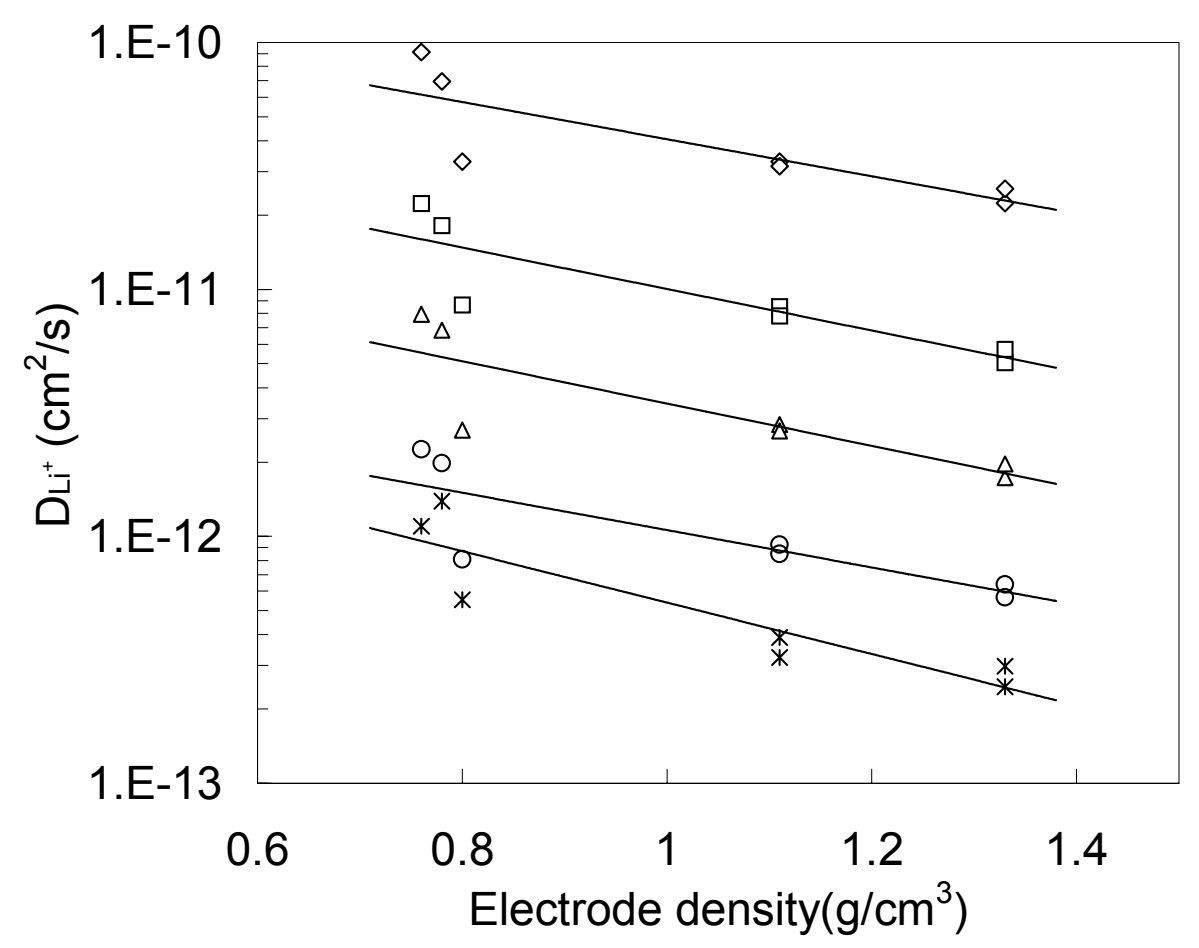

Fig. 11. Chemical diffusion coefficient of $\mathrm{Li}$ ion on $\mathrm{x}$ in $\mathrm{Li}_{\mathrm{x}} \mathrm{C}_{6}$ calculated from EIS; $(\diamond)$ $\mathrm{x}=0.1,(\square) \mathrm{x}=0.2,(\triangle) \mathrm{x}=0.3,(\bigcirc) \mathrm{x}=0.4,(*) \mathrm{x}=0.6$ 